\title{
Current perspectives in treating negative symptoms of schizophrenia: A narrative review (Review)
}

\author{
OCTAVIA O. CĂPĂȚîNĂ, IOANA V. MICLUȚIA and MIHAELA FADGYAS-STĂNCULETE
}

Department of Neurosciences, 'Iuliu Hațieganu' University of Medicine and Pharmacy, 400012 Cluj-Napoca, Romania

Received October 16, 2020; Accepted November 17, 2020

DOI: $10.3892 / \mathrm{etm} .2021 .9707$

\begin{abstract}
The negative symptoms of schizophrenia are an unmet treatment target as currently approved treatments mostly control positive symptoms. The persistence of these symptoms holds back the patient's reinstatement in society, making them incapable of fulfilling their social, professional, or family roles. There is overwhelming research evidence suggesting that the negative symptoms of schizophrenia are associated with poorer functioning and lower quality of life than positive symptoms, confirming the need for developing new treatments for this particular category of symptoms. This present review aims to review clinical trials addressing novel pharmacological approaches addressing primary negative symptoms of schizophrenia. We overview both monotherapies, first-generation and second-generation antipsychotics, and add-on therapies, including psychostimulants, anti-inflammatory drugs, antidepressants, molecules targeting glutamatergic, cholinergic or serotonergic systems and hormones. Our findings suggest that the primary negative symptoms of schizophrenia may be mitigated by adjunctive therapies, and we highlight the pharmacological agents that have proven superior efficacy. Novel compounds such as cariprazine and MIN-101, to date, show promising results, but large clinical trials are needed to test their efficacy and safety.
\end{abstract}

\section{Contents}

1. Introduction

2. Literature review methodology

3. The dopamine system

4. Glutamatergic pathway

5. The inflammatory pathway

Correspondence to: Dr Mihaela Fadgyas-Stănculete, Department of Neurosciences, 'Iuliu Hațieganu' University of Medicine and Pharmacy, 43 Victor Babes Street, 400012 Cluj-Napoca, Romania E-mail: mihaelastanculete@yahoo.com

Key words: pharmacological treatment, antipsychotic add-on therapies, primary negative symptoms, schizophrenia, deficit syndrome
6. Serotonin system

7. Cholinergic system

8. Hormones

9. Conclusions

\section{Introduction}

Negative symptoms have long been recognized as a core feature of schizophrenia since the first description of the disease and remain unmet treatment targets. Even though negative symptoms represent a heterogeneous syndrome, there is now a consensus regarding its constitutive factors, which encompass blunted affect, alogia, social withdrawal, avolition, and anhedonia (1). An important distinction has been made in the last decades between primary and secondary negative symptoms. The primary ones are considered to be intrinsic to the disease. Secondary ones are the result of other categories of symptoms such as positive symptoms, depressive symptoms, cognitive deficits, extrapyramidal side effects, or social deprivation or chronic consumptive disorders. Unlike primary negative symptoms, which are not adequately targeted by current interventions, secondary negative symptoms respond to treatment of the underlying cause $(2,3)$.

There are several reasons why there is a growing interest in developing treatments, specifically targeting primary negative symptoms. First, negative symptoms of schizophrenia are a significant contributor to poor functional outcomes and low quality of life to a greater extent than positive symptoms (4-6). The high prevalence of these symptoms was demonstrated by an epidemiological study conducted by Bobes et al in 2010, which established a prevalence rate of approximately $58 \%$, for at least one primary negative symptom in patients diagnosed with schizophrenia (7). The lack of approved treatments for this group of symptoms emerges from the fact that no treatment has been proven effective and reliable from large clinical trials $(5,8)$.

\section{Literature review methodology}

The present review aims to provide a general overview of the recent research into pharmacological treatment approaches targeting negative symptoms of schizophrenia. This is a selective review of the literature published between 1998 and 2019. We decided to focus on this period, as many advances have 
been achieved to treat negative symptoms. Moreover, during this period, research attention shifted from the positive to the negative symptoms of schizophrenia. The following databases PubMed, Web of Science and Elsevier were searched, using the following combinations of terms: 'Negative symptoms in schizophrenia', AND 'antipsychotic treatment', 'antidepressant treatment', 'cholinergic', 'glutamate', 'hormones', to identify clinical trials designed for the pharmacological treatment of primary negative symptoms. We included only clinical trials, reviews, and meta-analyses, published in English, on human subjects, which used clinically validated scales for schizophrenia and negative symptoms (e.g., Positive and Negative Syndrome Scale, Brief Negative Symptoms Scale or Negative Symptoms assessment Scale-16) and which differentiated between primary, secondary negative symptoms.

We focused only on compounds targeting the dopaminergic system, the glutamate system, the serotonergic system, the cholinergic system, or the inflammatory pathway and hormones, which have been tested as potential treatments for primary negative symptoms (Table I).

\section{The dopamine system}

First-generation antipsychotics. First-generation antipsychotics include chlorpromazine, fluphenazine, haloperidol, and their mechanism of action is based on blocking D2 dopamine receptors. Even though it was thought that these drugs ameliorate negative symptoms, further research has shown that the improvements appeared only in secondary negative symptoms as a result of the improvements in positive symptoms (9).

Atypical antipsychotics. Second-generation antipsychotics, also known as atypical antipsychotics (AA) were introduced in the late 1980s, and they were thought to be a significant breakthrough in the treatment of negative symptoms, due to their heterogeneous mechanism of action. In addition to the blocking in various degrees of D2 dopamine receptors, they possess a wide variety of affinities for other neurotransmitter receptors. While initially second-generation antipsychotics appeared to be more efficacious than first-generation antipsychotics in treating primary negative symptoms, well-conducted meta-analyses showed that their efficacy was attributable to changes in secondary negative symptoms $(2,8)$. They were found to have fewer extrapyramidal side effects and, additionally, they have antidepressant properties related to their affinity for serotonergic receptors.

Two second-generation antipsychotics, amisulpride and clozapine, were believed to have a superior effect on negative symptoms than other atypical antipsychotics. The limitations found for many trials evaluating clozapine's efficacy for negative symptoms were given by the fact that the symptoms were evaluated globally and were not divided in primary and secondary $(2,3)$. A study worth mentioning from 1998 conducted by Buchanan et al (10), categorized the sample of patients in deficit or non-deficit schizophrenia, and evaluated the response to clozapine for each group. The results showed that the apparent benefit of clozapine for treating negative symptoms arises from its greater efficacy in treating positive symptoms, and, therefore, only secondary negative symptoms benefit from clozapine treatment with the disadvantage of overweight which could lead to depression and self-stigmatization (11). Other meta-analyses and well-designed clinical trials support these findings $(9,12,13)$. Amisulpride, another second-generation antipsychotic, was approved in some European countries for the treatment of negative symptoms, because of its high affinity for dopamine D2 and D3 receptors and low affinity for 5-HT1A, 5-HT2A receptors. Amisulpride has received particular attention, but even though the first results were encouraging, meta-analyses revealed that the apparent benefits in improving negative symptoms were attributable to its ability to ameliorate depressed mood $(2,14,15)$.

The Clinical Antipsychotic Trials of Intervention Effectiveness (CATIE) study was designed in 2000 to compare typical vs. atypical antipsychotics' efficacy. Contrary to the study hypothesis, the efficacy of the two generations of antipsychotics was similar, except for olanzapine. In addition, there were no significant differences regarding negative symptomatology, except for olanzapine, which showed better effects than all the other agents (16). These results were also supported by studies conducted by Pilla Redy et al (17) and Shafti and Gilanipoor (18), emphasizing the superiority of olanzapine and its antidepressant effects.

Asenapine is an atypical antipsychotic antagonist of various dopaminergic, serotonergic, and $\alpha$ adrenergic receptors, and it has an appreciably high affinity for 5HT2A receptors than D2 receptors. However, its antagonism of $\alpha 2$ adrenoceptors is believed to improve negative symptoms and cognitive function in schizophrenia (19). A phase 2 efficacy study suggested that asenapine was superior to risperidone in decreasing negative symptoms in schizophrenia at six weeks (20). Another clinical trial comparing olanzapine and asenapine showed no significant difference over 26 weeks but indicated superiority for asenapine with continued treatment for 52 weeks (21).

A novel antipsychotic drug cariprazine, which is a dopamine D3/D2 receptor partial agonist, D3-preferring, and serotonin 5-HT1A receptor partial agonist, showed its efficacy in a prospectively designed trial targeting persistent, predominant negative symptoms in patients with schizophrenia in comparison to risperidone (22). We found another two randomized, double-blind, placebo- and active-controlled studies in patients with acute schizophrenia and moderate/severe negative symptoms, in which cariprazine was associated with significant improvement in negative symptoms compared with aripiprazole and placebo (23).

Psychostimulants. Clinical evidence suggests that psychostimulants, dopamine agonists, can induce psychotic symptoms in healthy individuals and exacerbate them in schizophrenic patients. However, it has also been suggested that these agents could manage negative symptoms due to their ability to stimulate the dopamine mesocortical pathway (8). A study from 2013 examined the efficacy of lisdexamfetamine dimesylate as adjunctive therapy to antipsychotics and showed a significant improvement in negative symptomatology, but other clinical trials did not support these findings $(24,25)$.

\section{Glutamatergic pathway}

Deficient signaling through the N-methyl-D-aspartate (NMDA) receptor is hypothesized to underlie many signs 


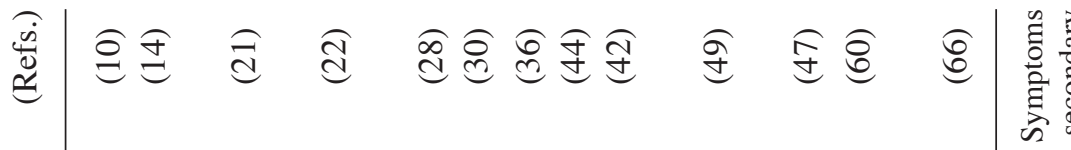

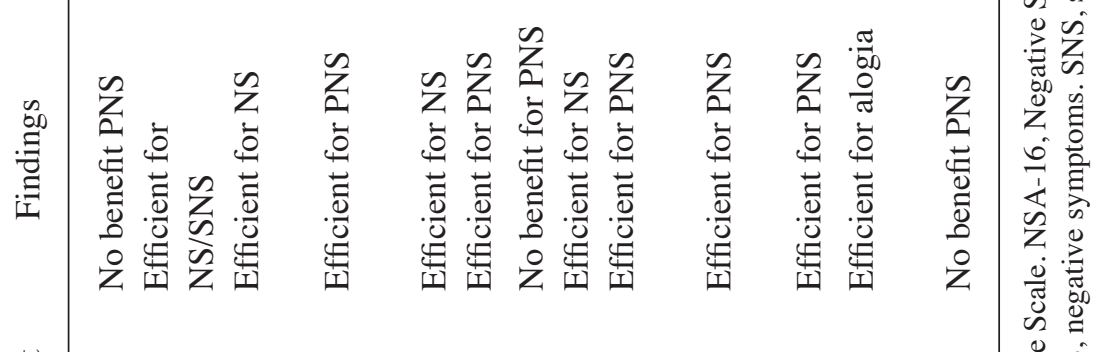

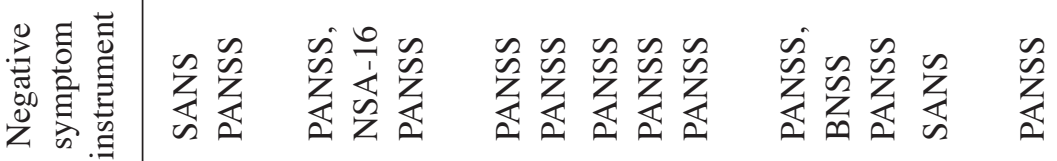

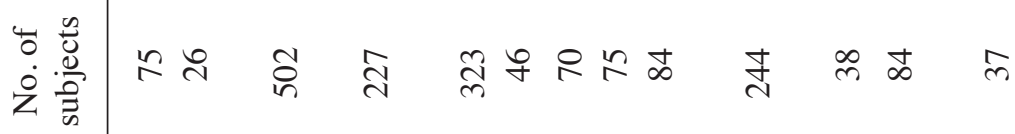

产宗

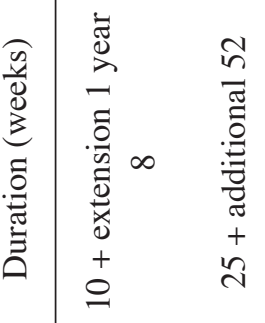

(1) $\infty \simeq \infty \simeq \simeq \simeq \simeq \simeq \infty$

客

言

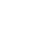

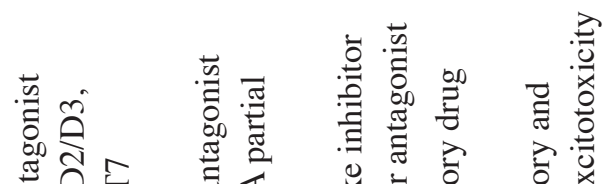

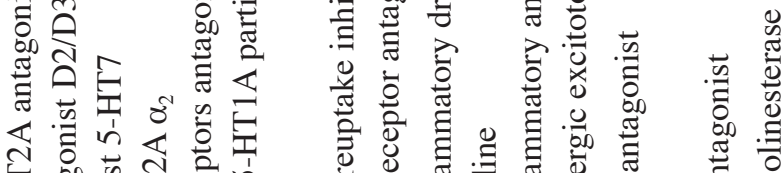

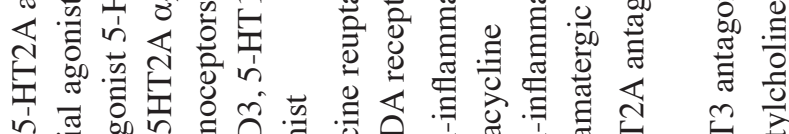

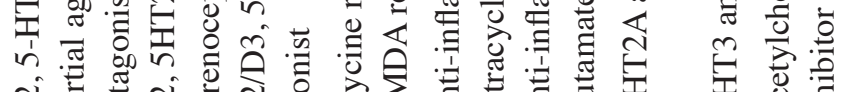

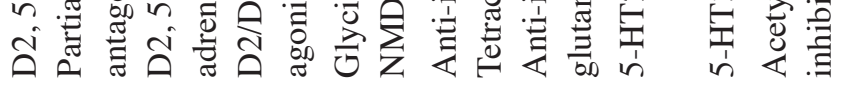

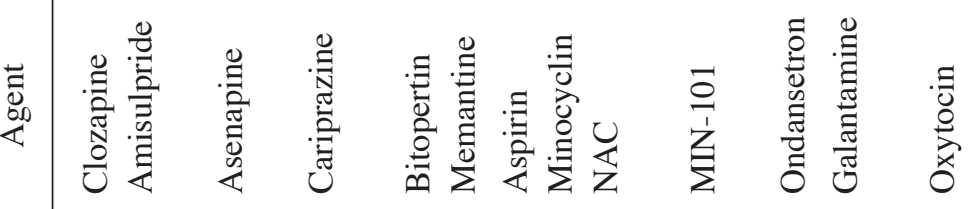

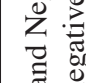

$\sum_{\text {窟 }}$

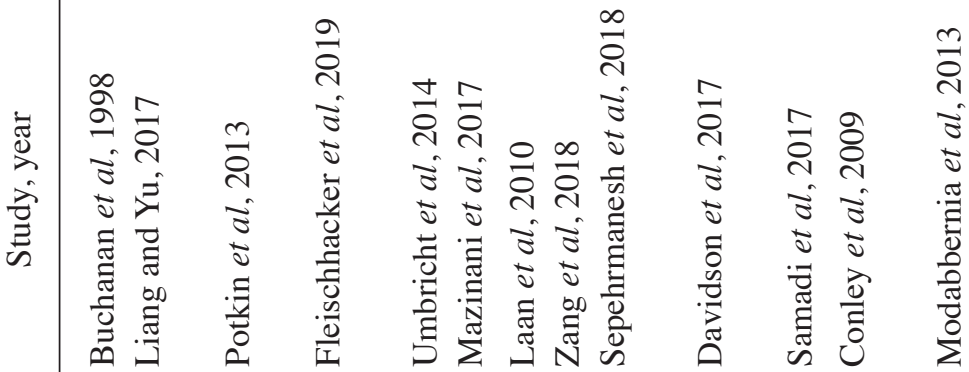

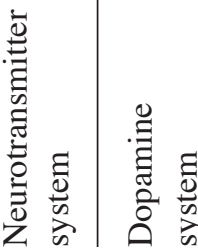

In

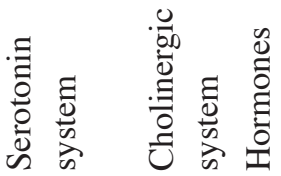

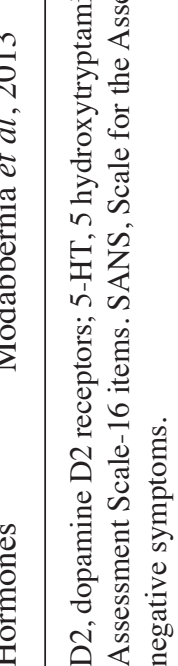


and symptoms associated with schizophrenia, in particular negative symptoms. Glycine acts as a co-agonist NMDA receptor. The most studied agents include D-cycloserine and glycine, which target the glycine site of NMDA receptors as partial agonists, but the results were inconsistent across trials $(8,9,26)$. The Cognitive and Negative Symptoms in Schizophrenia Trial (CONSIST) was the most significant trial testing D-cycloserine and glycine antipsychotic-adjunctive therapy. In this trial, the placebo's efficacy was comparable to treatment, even though there were reported effects in some patient subpopulations $(3,27)$. The blockade of the glycine transporter type 1 inhibits glycine reuptake, and through this elevates synaptic glycine concentrations. This led to the hypothesis that it can be an effective strategy to enhance NMDA receptor transmission. Bitopertin is a glycine reuptake inhibitor; its efficacy and tolerability were evaluated in patients with schizophrenia and predominantly negative symptoms, who were stable while taking an antipsychotic treatment in several studies $(28,29)$. However, an only small improvement was associated with bitopertin, and this taken together with the varying placebo response, purported the conclusion that adjunctive bitopertin treatment offers only modest benefit (29).

Various studies have aimed to test the efficacy of memantine, a weak NMDA receptor antagonist, in treating negative symptoms. The results of these trials were encouraging, as $20 \mathrm{mg}$ of memantine as add-on therapy to risperidone $(30,31)$ or clozapine (32) significantly improved negative symptoms. A meta-analysis from 2017 focused on memantine add-on to antipsychotic treatment for negative and cognitive symptoms of schizophrenia and concluded that it might be beneficial, especially for negative symptoms. However, it also underlined that the negative-symptom effect size might be associated with younger age in schizophrenia patients (33).

Preclinical and clinical data show that pregnenolone, a neurosteroid, and an anti-inflammatory drug could potentially mitigate GABA dysregulation and/or NMDA receptor hypofunction in patients with schizophrenia via the metabolism of other neurosteroids. An 8-week, pregnenolone add-on therapy to antipsychotic medications, placebo-controlled trial reported a reduction in the severity of negative symptoms in recent-onset schizophrenia if it was not used in conjunction with mood stabilizers (34).

\section{The inflammatory pathway}

Accumulating evidence shows that anti-inflammatory drugs may play an important role in schizophrenia, as a propensity towards a pro-inflammatory status in the brain of patients with schizophrenia is widely accepted. Additionally, it has been suggested that higher levels of interleukin (IL)-6 and tumor necrosis factor (TNF)- $\alpha$ are related to negative symptoms, mainly flat affect (35). Some of the examined anti-inflammatory agents include aspirin, celecoxib, bexarotene, omega-3 fatty acids, pregnenolone, $\mathrm{N}$-acetylcysteine (NAC), minocycline, bexarotene, davunetide, dextromethorphan, melatonin, minocycline, statins, varenicline, and Withania somnifera extract (36,37). A meta-analysis from 2019, which included 56 studies indicated that the following compounds: Bexarotene, celecoxib, davunetide, dextromethorphan, fatty acids, pregnenolone, statins, and varenicline showed no significant effect and the agents with significant effect in at least two studies were aspirin, minocycline, and NAC (38).

The effects of aspirin as an adjunct treatment for schizophrenia were also reviewed in 2019 by Schmidt and colleagues. However, it was impossible to conclude because the evidence produced by the trials was weak, therefore inconclusive (39).

The association between schizophrenia with mitochondrial abnormalities, glutathione deficit, and increased brain oxidative stress has been reported in several studies. The potential benefit of the antioxidant and anti-inflammatory capacity and mitigation of glutamatergic excitotoxicity of NAC was investigated in several clinical trials for its benefits regarding negative symptoms, with inconsistent results (40-42). A randomized, multicenter, double-blind, placebo-controlled study, published in 2008 by Berk et al evaluating the safety and efficacy of NAC in chronic schizophrenia, reported that NAC was less efficacious than placebo after eight weeks, but produced significant reductions in Positive and Negative Syndrome Scale (PANSS) negative, general, and total scores vs. placebo after 24 weeks (43).

The efficacy of minocycline, a second-generation tetracycline, was assessed as adjunctive therapy to risperidone and showed a significant improvement in negative symptoms of schizophrenia in a 3-month, double-blind, randomized, placebo-controlled clinical trial. The proposed potential mechanism underlying its efficacy was the reduction in pro-inflammatory cytokines (44). A comprehensive meta-analysis conducted in 2014 examining minocycline, as add-on therapy, in patients with schizophrenia receiving antipsychotic agents, reported its superiority, compared to a placebo, in improving the general psychopathology of schizophrenia, especially negative symptoms (45).

\section{Serotonin system}

Serotonin (5-HT) 3 receptor antagonists are widely used to prevent nausea and vomiting, mostly in patients receiving chemotherapy for cancer. Small studies have suggested that this class of medication could be useful as an adjunct therapy to alleviate the cognitive and negative symptoms of schizophrenia $(46,47)$. A meta-analysis including three tropisetron plus risperidone studies, one ondansetron plus risperidone study, one ondansetron plus haloperidol, and granisetron plus risperidone study, all selective 5-HT3 receptor antagonist, used in schizophrenia stable patients revealed their beneficial effect on the psychopathology, especially negative symptoms when compared to controls. Also, the add-on selective 5-TH3 receptor antagonists seemed to be well-tolerated treatments (48).

MIN-101 is a new compound with affinities for 5-HT2A and sigma-2 receptors and no direct dopamine affinities, which demonstrated efficacy in reducing negative symptoms in stable schizophrenia patients compared to a placebo (49).

Antidepressants have been widely used in clinical trials targeting negative symptoms, but the major methodological limitation in evaluating their efficacy is the difficulty to distinguish between improvements in primary negative symptoms 
vs. the ones secondary to depression. Two major meta-analyses evaluated antidepressants, selective serotonin reuptake inhibitors, tricyclic antidepressants, tetracyclic antidepressants, mirtazapine vs. placebo antipsychotic add-on therapy for negative symptoms $(50,51)$. Both indicated a significant benefit, but with a medium overall size effect. Some authors recommend antidepressants in addition to antipsychotics in treatment for schizophrenia in patients with persistent negative symptoms (52). Although most studies report improvement for negative symptoms with combined antidepressant/antipsychotic treatment [mirtazapine/olanzapine (53), mirtazapine/risperidone (54), escitalopram/aripiprazole (55)], other studies did not replicate these findings $(56,57)$. Most clinical trials evaluated either serotonin selective reuptake inhibitors or mirtazapine, but one recent study indicated that duloxetine seems to be a tolerable and efficacious agent, as an adjuvant to risperidone, for primary negative symptoms of schizophrenia (58). A randomized controlled trial reported another interesting finding on treatment-resistant schizophrenia patients augmented with escitalopram, which found an improvement in persistent negative symptoms and decreased IL-6 and C-reactive protein (59).

\section{Cholinergic system}

The cholinergic system is composed of muscarinic and nicotinic receptors, which both use acetylcholine as a neurotransmitter. The cholinergic model for schizophrenia suggests that the alterations of the acetylcholine signaling system and the decrease in muscarinic and nicotinic receptors may contribute to the development of cognitive and negative symptoms. In addition, the observations that high doses of anticholinergic drugs can induce psychotic symptoms supports this theory $(8,52)$. Acetylcholinesterase inhibitors (donepezil, rivastigmine, galantamine), currently used for dementia, have been studied as a potential treatment for negative symptoms, as they increase cholinergic activity (60). Two meta-analyses examined the effects of cholinergic agents as adjunctive therapies targeting negative symptoms. The results showed that acetylcholinesterase inhibitors may have benefits in the treatment of negative symptoms $(61,62)$.

\section{Hormones}

The endocrine model for schizophrenia has been proposed because of the gender differences in illness onset and course, given the lower age of onset in men and the higher prevalence of onset in premenopausal women. It has been hypothesized that estrogen has a protective role. Several studies have evaluated the role of estrogen as an antipsychotic add-on therapy for negative symptoms, in both women and men, with promising results $(63,64)$. However, a quantitative review on estrogen augmentation in schizophrenia, which included only double-blind, placebo-controlled, randomized studies, reported that estrogen, especially estradiol, could be an effective augmentation strategy, but only in women with schizophrenia (65).

Oxytocin, a neuropeptide known to moderate social behaviors, has been investigated as a potential therapeutic compound for negative symptoms of schizophrenia in recent years (66). A systematic review and meta-analysis of randomized controlled trials comparing oxytocin augmentation therapy with placebo in patients with schizophrenia, published in 2016, indicated that oxytocin was superior to placebo for decreasing the PANSS general subscale scores. However, there were no differences from placebo in total, positive, or negative symptoms scores. However, a sensitivity analysis, which included oxytocin administration on consecutive day studies, did support its superior efficacy compared to placebo in negative symptoms (67).

\section{Conclusions}

In this study, we reviewed some of the potentially effective therapeutic agents that have been considered for the treatment of negative symptoms of schizophrenia, and we attempted to provide a general overview. However, given the extent of this topic, we must mention that we highlighted only the most investigated mechanisms of action and that other drugs that we have not mentioned are being actively explored.

In the last few decades, clinicians have started placing more emphasis on managing the negative symptoms of schizophrenia as these symptoms are poorly managed by current treatments and account for the impaired functioning and low quality of life of these patients.

Although the initial excitement surrounding the breakthrough in second-generation antipsychotics for treating negative symptoms has disappeared, there is some evidence that certain second-generation antipsychotics (olanzapine, clozapine, amisulpride and asenapine) may confer benefits in treating negative symptoms. However, it is difficult to distinguish whether these improvements are related only to secondary negative symptoms.

Newer compounds targeting primary negative symptoms, cariprazine, and MIN-101, have shown promising results, but more extensive clinical trials are needed to consolidate these findings.

Several antipsychotic add-on therapies (cholinergic, glutamatergic and serotonergic agents, anti-inflammatory drugs and hormones) are currently under investigation. However, the results in these areas are still controversial due to the low number of trials and to issues arising from trial design (short duration, small sample size, variable definitions for negative symptoms, trials not designed for primary negative symptoms); thus, more clinical trials are needed to establish the efficacy for these treatments.

Significant progress has been made in the last decade in defining negative symptoms, distinguishing between primary and secondary negative symptoms, and quantifying negative symptoms, but despite this progress, there are still few clinical trials that focus predominantly on negative symptoms. Some of the proposed directions for future research follow a proper methodology for measuring persistent negative symptoms in clinical trials and identifying different biomarkers that define subgroups of patients with negative symptoms and try to find a common mechanism of action in these subpopulations.

\section{Acknowledgements}

Not applicable. 


\section{Funding}

No funding was received.

\section{Availability of data and materials}

All information in this review was documented by relevant references.

\section{Authors' contributions}

OOC, IVM and MFS designed the review. OOC and MFS performed the literature search, selection of articles and wrote the paper. All authors read and approved the final manuscript.

\section{Ethics approval and consent to participate}

Not applicable.

\section{Patient consent for publication}

Not applicable.

\section{Competing interests}

The authors declare that they have no competing interests.

\section{References}

1. Kirkpatrick B, Fenton WS, Carpenter WT Jr and Marder SR: The NIMH-MATRICS consensus statement on negative symptoms. Schizophr Bull 32: 214-219, 2006.

2. Huhn M, Nikolakopoulou A, Schneider-Thoma J, Krause M, Samara M, Peter N, Arndt T, Bäckers L, Rothe P, Cipriani A, et al: Comparative efficacy and tolerability of 32 oral antipsychotics for the acute treatment of adults with multi-episode schizophrenia: A systematic review and network meta-analysis. Lancet 394: 939-951, 2019.

3. Buchanan RW: Persistent negative symptoms in schizophrenia: An overview. Schizophr Bull 33: 1013-1022, 2007.

4. Căpățînă $\mathrm{O}$ and Micluția I: Internalized stigma as a predictor of quality of life in schizophrenia. J Evid Based Psychother 19: 35-53, 2018.

5. Rabinowitz J, Levine SZ, Garibaldi G, Bugarski-Kirola D, Berardo CG and Kapur S: Negative symptoms have greater impact on functioning than positive symptoms in schizophrenia: Analysis of CATIE data. Schizophr Res 137: 147-150, 2012.

6. Salvan H, Stanculete M and Macrea R: Frequency of sexual dysfunction in patients with schizophrenia. Eur Psychiatry 22 (Suppl): S138, 2007.

7. Bobes J, Arango C, Garcia-Garcia M and Rejas J; CLAMORS Study Collaborative Group: Prevalence of negative symptoms in outpatients with schizophrenia spectrum disorders treated with antipsychotics in routine clinical practice: Findings from the CLAMORS study. J Clin Psychiatry 71: 280-286, 2010.

8. Tsapakis EM, Dimopoulou T and Tarazi FI: Clinical management of negative symptoms of schizophrenia: An update. Pharmacol Ther 153: 135-147, 2015.

9. Murphy BP, Chung YC, Park TW and McGorry PD: Pharmacological treatment of primary negative symptoms in schizophrenia: A systematic review. Schizophr Res 88: 5-25, 2006.

10. Buchanan RW, Breier A, Kirkpatrick B, Ball P and Carpenter WT Jr: Positive and negative symptom response to clozapine in schizophrenic patients with and without the deficit syndrome. Am J Psychiatry 155: 751-760, 1998.

11. Puia IC, Stanculete MF, Hopulele-Petri A, Muresan D and Puia A: Patients' perception of weight-related stigma in a Romanian sample. J Evid Based Psychother 17: 147-157, 2017.
12. Asenjo Lobos C, Komossa K, Rummel-Kluge C, Hunger H, Schmid F, Schwarz S and Leucht S: Clozapine versus other atypical antipsychotics for schizophrenia. Cochrane Database Syst Rev: CD006633, 2010.

13. McEvoy JP, Lieberman JA, Stroup TS, Davis SM, Meltzer HY, Rosenheck RA, Swartz MS, Perkins DO, Keefe RS, Davis CE, et al: CATIE Investigators: Effectiveness of clozapine versus olanzapine, quetiapine, and risperidone in patients with chronic schizophrenia who did not respond to prior atypical antipsychotic treatment. Am J Psychiatry 163: 600-610, 2006.

14. Liang Y and $\mathrm{Yu} \mathrm{X:} \mathrm{Effectiveness} \mathrm{of} \mathrm{amisulpride} \mathrm{in} \mathrm{Chinese}$ patients with predominantly negative symptoms of schizophrenia: A subanalysis of the ESCAPE study. Neuropsychiatr Dis Treat 13: 1703-1712, 2017.

15. Krause M, Zhu Y, Huhn M, Schneider-Thoma J, Bighelli I, Nikolakopoulou A and Leucht S: Antipsychotic drugs for patients with schizophrenia and predominant or prominent negative symptoms: A systematic review and meta-analysis. Eur Arch Psychiatry Clin Neurosci 268: 625-639, 2018.

16. Marder S, Fleischhacker WW, Earley W, Lu K, Zhong Y, Németh G, Laszlovszky I, Szalai E and Durgam S: Efficacy of cariprazine across symptom domains in patients with acute exacerbation of schizophrenia: Pooled analyses from 3 phase II/III studies. Eur Neuropsychopharmacol 29: 127-136, 2019.

17. Pilla Reddy V, Kozielska M, Suleiman AA, Johnson M, Vermeulen A, Liu J, de Greef R, Groothuis GM, Danhof M and Proost JH: Pharmacokinetic-pharmacodynamic modelling of antipsychotic drugs in patients with schizophrenia: Part II: The use of subscales of the PANSS score. Schizophr Res 146: 153-161, 2013.

18. Shafti SS and Gilanipoor A: A comparative study between olanzapine and risperidone in management of schizophrenia. Schizophr Res Treat 2014: 307202, 2014.

19. Balaraman R and Gandhi H: Asenapine, a new sublingual atypical antipsychotic. J Pharmacol Pharmacother 1: 60-61, 2010.

20. Potkin SG, Cohen M and Panagides J: Efficacy and tolerability of asenapine in acute schizophrenia: A placebo- and risperidonecontrolled trial. J Clin Psychiatry 68: 1492-1500, 2007.

21. Potkin SG, Phiri P, Szegedi A, Zhao J, Alphs L and Cazorla P: Long-term effects of asenapine or olanzapine in patients with persistent negative symptoms of schizophrenia: A pooled analysis. Schizophr Res 150: 442-449, 2013.

22. Fleischhacker W, Galderisi S, Laszlovszky I, Szatmári B, Barabássy Á, Acsai K, Szalai E, Harsányi J, Earley W, Patel M and Németh G: The efficacy of cariprazine in negative symptoms of schizophrenia: Post hoc analyses of PANSS individual items and PANSS-derived factors. Eur Psychiatry 58: 1-9, 2019.

23. Earley W, Guo H, Daniel D, Nasrallah H, Durgam S, Zhong Y, Patel M, Barabássy Á, Szatmári B and Németh G: Efficacy of cariprazine on negative symptoms in patients with acute schizophrenia: A post hoc analysis of pooled data. Schizophr Res 204: 282-288, 2019.

24. Lasser RA, Dirks B, Nasrallah H, Kirsch C, Joseph Gao, Pucci ML, Knesevich MA and Lindenmayer JP: Adjunctive lisdexamfetamine dimesylate therapy in adult outpatients with predominant negative symptoms of schizophrenia: Open label and randomized controlled trial. Soc Psychiatry Psychiatr Epidemiol 38: 2140-2149, 2013.

25. Lindenmayer JP, Nasrallah H, Pucci M, James S and Citrome L: A systematic review of psychostimulant treatment of negative symptoms of schizophrenia: Challenges and therapeutic opportunities. Schizophr Res 147: 241-252, 2013.

26. Goff DC: D-cycloserine: An evolving role in learning and neuroplasticity in schizophrenia. Schizophr Bull 38: 936-941, 2012.

27. de Bartolomeis A, Sarappa C, Magara S and Iasevoli F: Targeting glutamate system for novel antipsychotic approaches: Relevance for residual psychotic symptoms and treatment resistant schizophrenia. Eur J Pharmacol 682: 1-11, 2012.

28. Umbricht D, Alberati D, Martin-Facklam M, Borroni E, Youssef EA, Ostland M, Wallace TL, Knoflach F, Dorflinger E, Wettstein JG, et al: Effect of bitopertin, a glycine reuptake inhibitor, on negative symptoms of schizophrenia: A randomized, double-blind, proof-of-concept study. JAMA Psychiatry 71: 637-646, 2014.

29. Singer P, Dubroqua S and Yee BK: Inhibition of glycine transporter 1: The yellow brick road to new schizophrenia therapy? Curr Pharm Des 21: 3771-3787, 2015.

30. Mazinani R, Nejati S and Khodaei M: Effects of memantine added to risperidone on the symptoms of schizophrenia: A randomized double-blind, placebo-controlled clinical trial. Psychiatry Res 247: 291-295, 2017. 
31. Rezaei F, Mohammad-Karimi M, Seddighi S, Modabbernia A, Ashrafi M, Salehi B, Hammidi S, Motasami H, Hajiaghaee R, Tabrizi M and Akhondzadeh S: Memantine add-on to risperidone treatment of negative symptoms in patients with stable schizophrenia. J Clin Psychopharmacol 33: 336-342, 2013.

32. de Lucena D, Fernandes BS, Berk M, Dodd S, Medeiros DW, Pedrini M, Kunz M, Gomes FA, Giglio LF, Lobato MI, et al: Improvement of negative and positive symptoms in treatment-refractory schizophrenia: A double-blind, randomized, placebo-controlled trial with memantine as add-on therapy to clozapine. J Clin Psychiatry 70: 1416-1423, 2009.

33. Kishi T, Matsuda Y and Iwata N: Memantine add-on to antipsychotic treatment for residual negative and cognitive symptoms of schizophrenia: A meta-analysis. Psychopharmacology (Berl) 234: 2113-2125, 2017

34. Ritsner MS, Bawakny $\mathrm{H}$ and Kreinin A: Pregnenolone treatment reduces severity of negative symptoms in recent-onset schizophrenia: An 8-week, double-blind, randomized add-on two-center trial. Psychiatry Clin Neurosci 68: 432-440, 2014

35. Momtazmanesh S, Zare-Shahabadi A and Rezaei N: Cytokine alterations in schizophrenia: An updated review. Front Psychiatry 10: 892, 2019.

36. Laan W, Grobbee DE, Selten JP, Heijnen CJ, Kahn RS and Burger H: Adjuvant aspirin therapy reduces symptoms of schizophrenia spectrum disorders: Results from a randomized, double-blind, placebo-controlled trial. J Clin Psychiatry 71: 520-527, 2010

37. Cho M, Lee TY, Kwak YB, Yoon YB, Kim M and Kwon JS: Adjunctive use of anti-inflammatory drugs for schizophrenia: A meta-analytic investigation of randomized controlled trials. Aust N Z J Psychiatry 53: 742-759, 2019.

38. Çakici N, van Beveren NJM, Judge-Hundal G, Koola MM and Sommer IEC: An update on the efficacy of anti-inflammatory agents for patients with schizophrenia: A meta-analysis. Psychol Med 49: 2307-2319, 2019.

39. Schmidt L, Phelps E, Friedel J and Shokraneh F: Acetylsalicylic acid (aspirin) for schizophrenia. Cochrane Database Syst Rev 8 : CD012116, 2019

40. Breier A, LiffickE, HummerTA, Vohs JL, Yang Z, Mehdiyoun NF, Visco AC, Metzler E, Zhang Y and Francis MM: Effects of 12-month, double-blind $\mathrm{N}$-acetyl cysteine on symptoms, cognition and brain morphology in early phase schizophrenia spectrum disorders. Schizophr Res 199: 395-402, 2018

41. FarokhniaM,Azarkolah A,AdinehfarF,Khodaie-Ardakani MR Hosseini SM, Yekehtaz H, Tabrizi M, Rezaei F, Salehi B, Sadeghi SM, et al: N-acetylcysteine as an adjunct to risperidone for treatment of negative symptoms in patients with chronic schizophrenia: A randomized, double-blind, placebo-controlled study. Clin Neuropharmacol 36: 185-192, 2013.

42. Sepehrmanesh Z, Heidary M, Akasheh N, Akbari H and Heidary M: Therapeutic effect of adjunctive $\mathrm{N}$-acetyl cysteine (NAC) on symptoms of chronic schizophrenia: A double-blind, randomized clinical trial. Prog Neuropsychopharmacol Biol Psychiatry 82: 289-296, 2018.

43. Berk M, Copolov D, Dean O, Lu K, Jeavons S, Schapkaitz I, Anderson-Hunt M, Judd F, Katz F, Katz P, et al: $\mathrm{N}$-acetyl cysteine as a glutathione precursor for schizophrenia-a double-blind, randomized, placebo-controlled trial. Biol Psychiatry 64: $361-368,2008$

44. Zhang L, Zheng H, Wu R, Zhu F, Kosten TR, Zhang XY and Zhao J: Minocycline adjunctive treatment to risperidone for negative symptoms in schizophrenia: Association with pro-inflammatory cytokine levels. Prog Neuropsychopharmacol Biol Psychiatry 85: 69-76, 2018.

45. Oya K, Kishi T and Iwata N: Efficacy and tolerability of minocycline augmentation therapy in schizophrenia: A systematic review and meta-analysis of randomized controlled trials. Hum Psychopharmacol 29: 483-491, 2014.

46. Bennett AC and Vila TM: The role of ondansetron in the treatment of schizophrenia. Ann Pharmacother 44: 1301-1306, 2010.

47. Samadi R, Soluti S, Daneshmand R, Assari S and Manteghi AA: Efficacy of risperidone augmentation with ondansetron in the treatment of negative and depressive symptoms in schizophrenia: A randomized clinical trial. Iran J Med Sci 42: 14-23, 2017.

48. Kishi T, Mukai T, Matsuda Y and Iwata N: Selective serotonin 3 receptor antagonist treatment for schizophrenia: Meta-analysis and systematic review. Neuromolecular Med 16: 61-69, 2014.
49. Davidson M, Saoud J, Staner C, Noel N, Luthringer E, Werner S, Reilly J, Schaffhauser JY, Rabinowitz J, Weiser M and Luthringer R: Efficacy and safety of MIN-101: A 12-week randomized, double-blind, placebo-controlled trial of a new drug in development for the treatment of negative symptoms in schizophrenia. Am J Psychiatry 174: 1195-1202, 2017.

50. Singh SP, Singh V, Kar N and Chan K: Efficacy of antidepressants in treating the negative symptoms of chronic schizophrenia: Meta-analysis. Br J Psychiatry 197: 174-179, 2010.

51. Rummel C, Kissling W and Leucht S: Antidepressants for the negative symptoms of schizophrenia. Cochrane Database Syst Rev: CD005581, 2006 doi: 10.1002/14651858 D005581.

52. Möller HJ: Management of the negative symptoms of schizophrenia: New treatment options. CNS Drugs 17: 793-823, 2003.

53. Caforio G, Di Giorgio A, Rampino A, Rizzo M, Romano R Taurisano P, Fazio L, De Simeis G, Ursini G, Blasi G, et al: Mirtazapine add-on improves olanzapine effect on negative symptoms of schizophrenia. J Clin Psychopharmacol 33: 810-812, 2013.

54. Cho SJ, Yook K, Kim B, Choi TK, Lee KS, Kim YW, Lee JE, Suh S, Yook KH and Lee SH: Mirtazapine augmentation enhances cognitive and reduces negative symptoms in schizophrenia patients treated with risperidone: A randomized controlled trial. Prog Neuropsychopharmacol Biol Psychiatry 35: 208-211, 2011.

55. Tsai CH, Chen TT and Huang WL: Combination of escitalopram and aripiprazole causes significant improvement of negative symptoms of simple schizophrenia. Psychiatry Clin Neurosci 68: 582-583, 2014.

56. Hinkelmann K, Yassouridis A, Kellner M, Jahn H, Wiedemann K and Raedler TJ: No effects of antidepressants on negative symptoms in schizophrenia. J Clin Psychopharmacol 33: 686-690, 2013.

57. Usall J, López-Carrilero R, Iniesta R, Roca M, Caballero M, Rodriguez-Jimenez R, Oliveira C, Bernardo M, Corripio I, Sindreu SD, et al: Double-blind, placebo-controlled study of the efficacy of reboxetine and citalopram as adjuncts to atypical antipsychotics for negative symptoms of schizophrenia. J Clin Psychiatry 75: 608-615, 2014

58. Nikbakhat MR, Arabzadeh S, Zeinoddini A, Khalili Z, Rezaei F, Mohammadinejad P, Ghaleiha A and Akhondzadeh S: Duloxetine add-on to risperidone for treatment of negative symptoms in patients with stable schizophrenia: Randomized double-blind placebo-controlled study. Pharmacopsychiatry 49: 162-169, 2016.

59. Ding N, Li Z and Liu Z: Escitalopram augmentation improves negative symptoms of treatment resistant schizophrenia patients-A randomized controlled trial. Neurosci Lett 681: 68-72, 2018.

60. Conley RR, Boggs DL, Kelly DL, McMahon RP, Dickinson D, Feldman S, Ball MP and Buchanan RW: The effects of galantamine on psychopathology in chronic stable schizophrenia. Clin Neuropharmacol 32: 69-74, 2009.

61. Choi KH, Wykes T and Kurtz MM: Adjunctive pharmacotherapy for cognitive deficits in schizophrenia: Meta-analytical investigation of efficacy. Br J Psychiatry 203: 172-178, 2013.

62. Singh J, Kour K and Jayaram MB: Acetylcholinesterase inhibitors for schizophrenia. Cochrane Database Syst Rev 1: CD007967, 2012.

63. Hayes E, Gavrilidis E and Kulkarni J: The role of estrogen and other hormones in the pathophysiology and treatment of schizophrenia. Schizophr Res Treat 2012: 540273, 2012.

64. Kulkarni J, de Castella A, Headey B, Marston N, Sinclair K, Lee S, Gurvich C, Fitzgerald PB and Burger H: Estrogens and men with schizophrenia: Is there a case for adjunctive therapy? Schizophr Res 125: 278-283, 2011.

65. Begemann MJ, Dekker CF, van Lunenburg M and Sommer IE: Estrogen augmentation in schizophrenia: A quantitative review of current evidence. Schizophr Res 141: 179-184, 2012.

66. Modabbernia A, Rezaei F, Salehi B, Jafarinia M, Ashrafi M, Tabrizi M, Hosseini SM, Tajdini M, Ghaleiha A and Akhondzadeh S: Intranasal oxytocin as an adjunct to risperidone in patients with schizophrenia: An 8-week, randomized, double-blind, placebo-controlled study. CNS Drugs 27: 57-65, 2013.

67. Oya K, Matsuda Y, Matsunaga S, Kishi T and Iwata N: Efficacy and safety of oxytocin augmentation therapy for schizophrenia: An updated systematic review and meta-analysis of randomized, placebo-controlled trials. Eur Arch Psychiatry Clin Neurosci 266: 439-450, 2016.

This work is licensed under a Creative Commons

Attribution-NonCommercial-NoDerivatives 4.0 International (CC BY-NC-ND 4.0) License. 